MATEC Web of Conferences 6, 05008 (2013)

DOI: $10.1051 /$ matecconf $/ 20130605008$

(C) Owned by the authors, published by EDP Sciences, 2013

\title{
Aggregate behaviour in concrete materials under high temperature conditions
}

\author{
G. Mazzucco ${ }^{1}$, C. Majorana ${ }^{1}$, V. Salomoni ${ }^{1}$ and G. Xotta ${ }^{2}$ \\ 1 Department of Civil, Environmental and Architectural Engineering (DICEA), University of \\ Padova, via F. Marzolo 9, 35131 Padova, Italy \\ 2 Department of Civil and Environmental Engineering, Cullen College of Engineering, \\ University of Houston, N107 Engineering Building 1, Houston, TX 77204-4003, USA
}

\begin{abstract}
Concrete under high temperature conditions is a topic of wide interest for applications in several engineering fields, from nuclear to civil as well as building engineering.
\end{abstract}

Although this material generally provides adequate fire resistance for most applications, the exposure to elevated temperature results in degradation of its mechanical properties and reduction of cross-section area through spalling.

Traditionally concrete is considered as a homogeneous material, idealized as a continuum medium with average properties (macroscopic approach), but concrete is a highly heterogeneous material and its composite behaviour is exceedingly complex.

To obtain a deeper understanding of the macroscopic constitutive behaviour of concrete, material models, in which the structure of concrete at lower levels is explicitly represented, have been developed in recent decades thanks to upgraded computer resources.

Specifically in this work the meso-scale level (see Fig. 1) is considered, which provides a more realistic description of concrete at the macro scale, influenced by the geometry and the properties of its components, and a better comprehension of several concrete phenomena, such as creep, shrinkage, damage and spalling.

At the meso-level, concrete is a composite material made of cement paste and coarse aggregates with a diameter from 5 to $30 \mathrm{~mm}$ and that occupy about the $50 \%$ of the concrete volume.

However, concrete is not just a two-phase composite; it has been found that the presence of grains in the paste causes a thin layer of matrix material surrounding each inclusion which is more porous than the bulk of the surrounding cement paste matrix. This layer is named interfacial transition zone ITZ (see Fig. 1b), which is known to play an important role in the performance of concrete during a fire.

In this paper, the effect of aggregates characterized by different porosities will be investigated, in order to catch the different damage scenarios (see Fig. 2) related to the different inclusions types and hence to understand the role of aggregate porosity on spalling when concrete is exposed to fire. For this purpose, the 3D fully coupled thermo-hydro-mechanical finite element code NEWCON3D [1] has been adopted, a code able to perform analysis of concrete at the meso scale level under high temperatures [2]. Particularly, it is assumed that creep of concrete obeys to the B3 model proposed by Bažant and Baweja [3], instead damage obeys to the Mazars'damage law [4] with non-local correction.

This is an Open Access article distributed under the terms of the Creative Commons Attribution License 2.0, which permits unrestricted use, distribution, and reproduction in any medium, provided the original work is properly cited. 


\section{MATEC Web of Conferences}

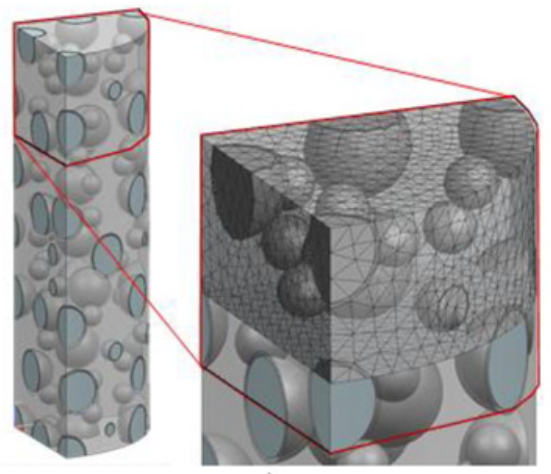

a)

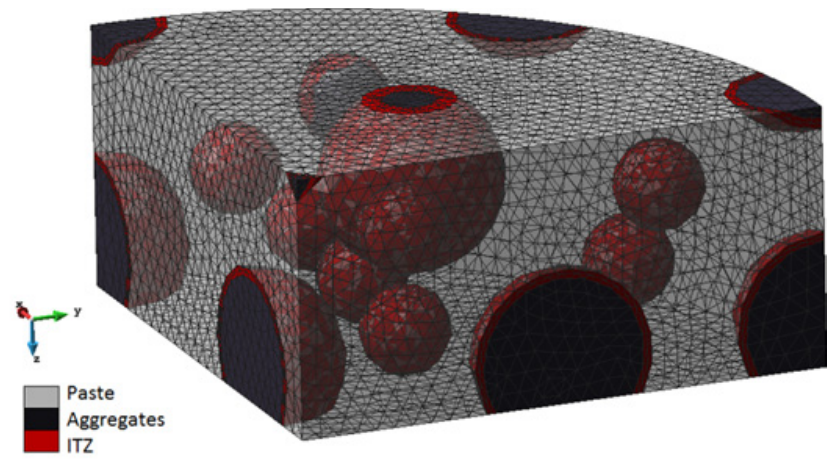

b)

Figure 1. Numerical model of concrete sample at 3D meso-level; a) concrete material characterization as composite material, with b) cement paste, aggregate and ITZ.

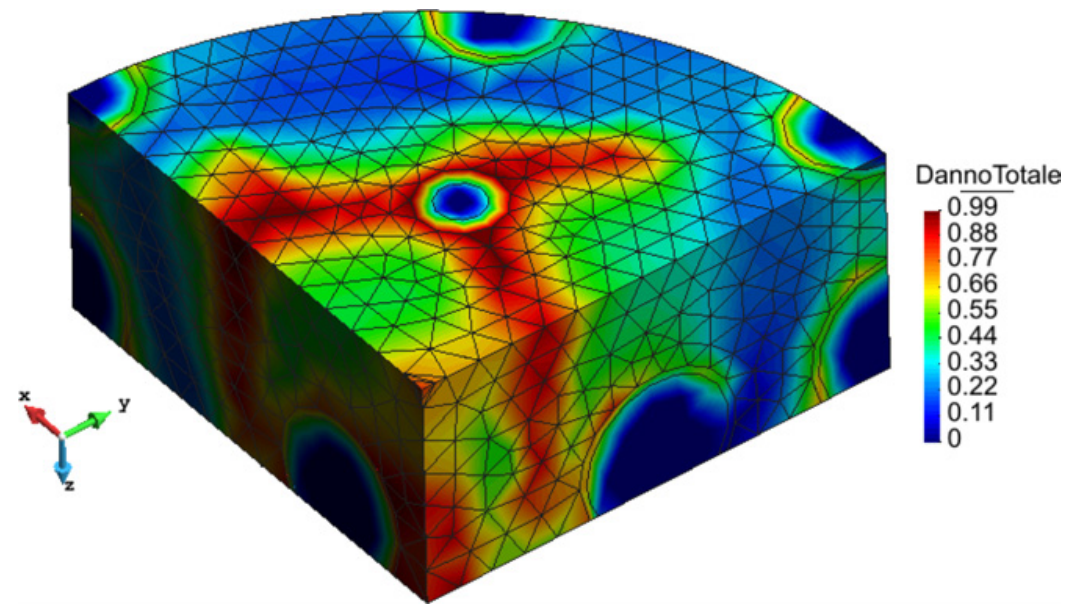

Figure 2. Contour damage.

\section{References}

[1] V.A. Salomoni, C.E. Majorana, G. Mazzucco, G. Xotta and G.A. Khoury, "Multiscale Modelling of Concrete as a Fully Coupled Porous Medium”, in: J.T. Sentowski (Ed.), Concrete Materials: Properties, Performance and Applications, Ch. 3, NOVA Publishers, pp. 171-231, (2009).

[2] C.E. Majorana, V.A. Salomoni, G. Mazzucco and G.A. Khoury, "An approach for modelling concrete spalling in finite strains", Mathematics and Computers in Simulation (Special Issue), Vol. 80 (8), pp. 1694-1712, (2010).

[3] Z. Bazant and S. Baweja, "Creep and shrinkage prediction model for analysis and design of concrete structures: Model B3", Adam Neville Symposium: Creep and Shrinkage-Structural Design Effects, ACI SP-194, A. Al-Manaseer Ed., Am. Concrete Institute, Farmington Hills, Michigan, pp. 1-83, (2000).

[4] J.A. Mazars, "Description of Micro and Macroscale Damage of Concrete structures", Eng. Frac. Mech. 25, pp. 729-737 (1986). 